\title{
SURFACE CHARACTERIZATION OF LIGNIN MATERIALS BY MEANS OF INVERSE GAS CHROMATOGRAPHY
}

\author{
ADAM VOELKEL, BEATA STRZEMIECKA, KATARZYNA ADAMSKA \& ŁUKASZ KLAPISZEWSKI \\ Poznan University of Technology, Poland
}

\begin{abstract}
Inverse gas chromatography was successfully used for the determination of Hansen solubility parameters (HSPs), as well as other surface parameters. Values of dispersive, polar and hydrogen bonding components of solubility parameters are used in the prediction of the behaviour of exemplary pharmaceutically active material in real mixtures, e.g. interactions with excipients. Values of HSPs are close to that obtained from additive method of the Hoftyzer/van Krevelen procedure. However, the second one can only be calculated if the structure of examined material is known. It is impossible to estimate it for mixtures or species which have unknown structures. In such a case, the use of inverse gas chromatography is suggested. Surface ability of lignin materials to various types of interaction might be also expressed by means of inverse gas chromatography derived surface parameters, including its heterogeneity. The examined materials were also characterized by DSC and TG-MS techniques.

Keywords: inverse gas chromatography, Hansen solubility parameters, Kraft lignin, surface characteristic.
\end{abstract}

\section{INTRODUCTION}

During the last 50 years, inverse gas chromatography (IGC) became an accepted, useful and widely used technique for physicochemical characterization of various types of materials [1]-[3]. The background and basic rules of IGC have been reported elsewhere [4], [5]. Here, it is worth to tell that material of interest is placed in short chromatographic column, placed in gas chromatograph oven. Carefully selected test solutes are injected and transported over the material (stationary phase) by mobile phase (gas). Retention of test solute depends on the magnitude of its interactions with the examined material. Depending on the nature of examined material various models should be applied for quantitative description of its properties. Generally, IGC might be divided into gas-liquid inverse gas chromatography and gas-solid inverse gas chromatography. In gas-solid systems the surface properties are most often described by using the surface energy parameters and its components corresponding to the ability to dispersive and specific interactions [2]-[6]. Properties of liquid materials were described by using Flory-Huggins interaction parameter as well as Hansen solubility parameters. Various procedures were applied to estimate HSPs as reported earlier [7]. Recently, the procedure enabling the estimation of HSPs for solid species was presented [8]-[10].

The aim of this paper was to characterize the surface properties of Kraft lignin by using inverse gas chromatographic procedure for gas-solid systems.

\section{BASIC RELATIONS}

The term solubility parameter was introduced in 1950 by Hildebrand and Scott [11], [12]. This parameter is defined as the square root of cohesive energy density:

where:

$$
\delta=(E / V)^{1 / 2}
$$

- $\quad V$ is the molar volume of the pure solvent.

- $E$ is energy of vaporization of the pure solvent. 
The relation (1) is valid for regular solutions. The use of this equation in systems where the specific interactions cannot be ignored might lead to serious errors. Therefore, the important step forward was done by Hansen in 1967. In the series of papers, he presented the idea of so-called Hansen solubility parameters (HSP) assuming that the total energy of vaporization of liquid consists of several individual parts [13]-[15]. The total energy of vaporization, $E$ is assumed to be sum of the individual energies corresponding to dispersive $E_{d}$, polar $E_{p}$ and hydrogen bonding $E_{h}$ interactions:

$$
\begin{gathered}
E=E_{d}+E_{p}+E_{h} \\
E / V=E_{d} / V+E_{p} / V+E_{h} / V \\
\delta_{T}^{2}=\delta_{d}^{2}+\delta_{p}^{2}+\delta_{h}^{2}
\end{gathered}
$$

The square of total solubility parameter is the sum of components corresponding to the ability to dispersive $d$, polar $p$ and hydrogen bonding $h$ interactions.

\subsection{HSP by gas-liquid inverse gas chromatography}

Inverse gas chromatography was applied relatively early for the determination of solubility parameter for polymers. However, the procedure proposed by Guillet and DiPaola-Baranyi is valid for systems obeying the rule of regular solutions [17], [18]. Determination of HSPs required taking into account specific interactions between test solutes and the examined material. In the series of papers new procedures were proposed [19]-[21]. Authors of this paper suggested the use of values of Flory-Huggins interaction parameter $\chi_{12}^{\infty}$

$$
\chi_{i 2}^{\infty}=\ln \left(\frac{273.15 \cdot R}{p_{i}^{o} \cdot V_{g^{\cdot}} \cdot M_{i}}\right)-\frac{p_{i}^{o}}{R \cdot T}\left(B_{i i}-V_{i}^{o}\right)+\ln \left(\frac{\rho_{i}}{\rho_{2}}\right)-\left(1-\frac{V_{i}^{o}}{V_{2}^{o}}\right),
$$

where:

- $\quad i$ and 2 denotes the solute and examined material, respectively.

- $V_{g i}-$ specific retention volume of the test solute.

- $M_{i}$ - the molecular weight of the solute.

- $p_{i}^{o}$ - the saturated vapor pressure of the solute.

- $B_{i i}-$ the second virial coefficient of the solute.

- $V_{i}^{o}$ - the molar volume of the test solute.

- $V_{2}^{o}$ - the molar volume of the examined material.

- $\rho$ - the density.

- $\quad R$ - the gas constant.

Adamska et al. found for test solutes and calculation of HSPs values from the following relation [22]:

where:

$$
\chi_{i 2}^{\infty}=\alpha \frac{V_{1}^{o}}{R T}\left(\left(\delta_{i, d}-\delta_{2, d}\right)^{2}+0.25\left(\delta_{i, p}-\delta_{2, p}\right)^{2}+0.25\left(\delta_{i, h}-\delta_{2, h}\right)^{2}\right),
$$

- $\alpha$-correction coefficient.

- $T$ - temperature of measurement.

Optimization of equation (5) leads to values of HSPs $\left(\delta_{2, d}, \delta_{2, p}, \delta_{2, h}\right)$ characterizing examined material. The total solubility parameter is then calculated from eqn (3). 


\subsection{HSP by gas-solid inverse gas chromatography}

Determination of solubility parameter for solid materials by means of inverse gas chromatography is based on the model of adsorption described by Snyder and Karger and requires the knowledge of value of adsorption energy for the respective test solutes [23], Snyder et al. [24].

According to Snyder et al. [24] model the molecule of test solute " $i$ " is adsorbed onto the surface of solid adsorbent " 2 ". From the energy balance, the following expression is derived for the energy of adsorption $\Delta E^{A}$ :

$$
-\Delta E_{i}^{A}=V_{i}\left(\delta_{i} \delta_{2}\right)
$$

Introducing Hansen concept of solubility parameter, one obtains:

$$
-\Delta E_{i}^{A}=V_{i}\left(\delta_{i d} \delta_{2 d}+\delta_{i p} \delta_{2 p}+\delta_{i h} \delta_{2 h}\right)
$$

The energy of adsorption is related to the specific retention volume by the following equation:

$$
\ln V_{i g}=-\left(\Delta E_{i}^{A} / R T\right)+\text { const }
$$

For $N$ test solutes system of $N$ equations is obtained:

where:

$$
\left(\begin{array}{c}
-\Delta E_{1}^{A} \\
\ldots \\
-\Delta E_{n}^{A} \\
\ldots \\
-\Delta E_{N}^{A}
\end{array}\right)=\left(\begin{array}{ccc}
V_{1} \delta_{1 d} & V_{1} \delta_{1 p} & V_{1} \delta_{1 h} \\
\ldots & \ldots & \ldots \\
V_{n} \delta_{n d} & V_{n} \delta_{n p} & V_{n} \delta_{n h} \\
\ldots & \ldots & \ldots \\
V_{N} \delta_{N d} & V_{N} \delta_{N p} & V_{N} \delta_{N h}
\end{array}\right) *\left(\begin{array}{c}
\beta_{1} \\
\ldots \\
\beta_{n} \\
\ldots \\
\beta_{N}
\end{array}\right)+\left(\begin{array}{c}
\varepsilon_{1} \\
\ldots \\
\varepsilon_{n} \\
\ldots \\
\varepsilon_{N}
\end{array}\right)
$$

- $\quad Y$ is the column vector containing the $N$ values of measured values of the energy of adsorption $\left(-\Delta E_{n}^{A}\right)$ of $N$ solutes.

- $X$ is the experimental matrix, formed of elements $\left(X_{n k}\right)$, where $X_{n k}=V_{n} \delta_{n k}$.

- $\quad V_{n}$ is the molar volume of the $n^{\text {th }}$ solute and $\delta_{n k}$ is one of the Hansen solubility parameters of type $k(k=d$, $p$, or $h)$ of the respective solute.

- The $\beta$ vector contains the real values of HSPs of the adsorbent, i.e. $\delta_{2 d}, \delta_{2 p}, \delta_{2 h}$.

- The $\varepsilon$ vector corresponds to the experimental errors, $\varepsilon_{n}$.

Values of the components of solubility parameter might be found by using equation (9) and $\delta_{T}$ is calculated from equation (3).

\section{EXPERIMENTAL}

\subsection{Material}

Kraft lignin (Sigma Aldrich, Germany) was used in all experiments. The biopolymer is a brown solid, which was dissolved in water. The average molecular mass is $\mathrm{M}_{\mathrm{W}} \sim 10,000$. In addition, lignin used contains up to $4 \%$ of sulfur.

\subsection{FTIR and TG-MS experiments}

Samples of Kraft lignin were characterized by FTIR and TG-MS. The presence of the expected functional groups was confirmed by Fourier transform infrared (FTIR) 
spectroscopy, using a Vertex 70 spectrophotometer (Bruker, Germany). The material was analyzed in the form of tablets, made by placing a mixture of anhydrous $\mathrm{KBr}$ (ca. $0.25 \mathrm{~g}$ ) and $1.5 \mathrm{mg}$ of the tested substance in a steel ring under a pressure of $10 \mathrm{MPa}$. The test was performed at a resolution of $0.5 \mathrm{~cm}^{-1}$ in the range $4000-400 \mathrm{~cm}^{-1}$. TG-MS curve was obtained using a thermogravimetric analyzer coupled to the MS (1 PYRISTGA/MS CLARUS 680 SQ8, Perkin Elmer, Waltham, MA, USA). The apparatus uses electron streams (EI) with energy $70 \mathrm{eV}$. The measurement was performed in a helium atmosphere (gas flow 40 $\mathrm{mL} / \mathrm{min}$ ) at a heating rate of $20 \mathrm{C} / \mathrm{min}$. The sample was heated up to $1000^{\circ} \mathrm{C}$, starting from $30^{\circ} \mathrm{C}$.

\subsection{IGC experiments}

IGC experiments were carried out using $30 \mathrm{~cm}$ long glass columns (I.D. $3 \mathrm{~mm}$ ) with inner walls modified by silanization. Temperature of the column was $30,40,50,60,70,80,90$, 100,110 and $120^{\circ} \mathrm{C}$. Temperature of injector and detector was equal to $180^{\circ} \mathrm{C}$. Measurements were performed at $0 \%$ relative humidity. The column was conditioned at a given temperature by 2 hours. Dead-time was determined using methane as inert gas. The carrier gas was helium (flow-rate $10 \mathrm{~cm}^{3} / \mathrm{min}$ ). The following compounds were used as test solutes: hexane, heptane, octane, nonane, decane, dichloromethane, ethanol, ethyl acetate, 1, 4-dioxane, acetonitrile. All test solutes were at least of analytical grade (purity $\geq 97 \%$ ).

Values of Hansen solubility parameters for lignin were determined from equations (8)-(10) and (3).

\section{RESULTS AND DISCUSSION}

Kraft lignin samples were characterized by means of FTIR and TG-MS technique. The presence of the expected functional groups was confirmed (Fig. 1). Characteristic bands were found at $\sim 3400 \mathrm{~cm}^{-1}$ for $-\mathrm{OH}$ groups, $2900 \mathrm{~cm}^{-1}$ for aliphatic $-\mathrm{CH}, 1600 \mathrm{~cm}^{-1}$ for aromatic ring $\mathrm{C}-\mathrm{C}, \sim 1200 \mathrm{~cm}^{-1}$ for $\mathrm{C}-\mathrm{O}$ of alcohols and phenols. At wavenumber about $1000 \mathrm{~cm}^{-1}$ the band for C-O-C can be seen. The band between 900 and $500 \mathrm{~cm}^{-1}$ can indicate 1,2,3,5-substituded aromatic rings.

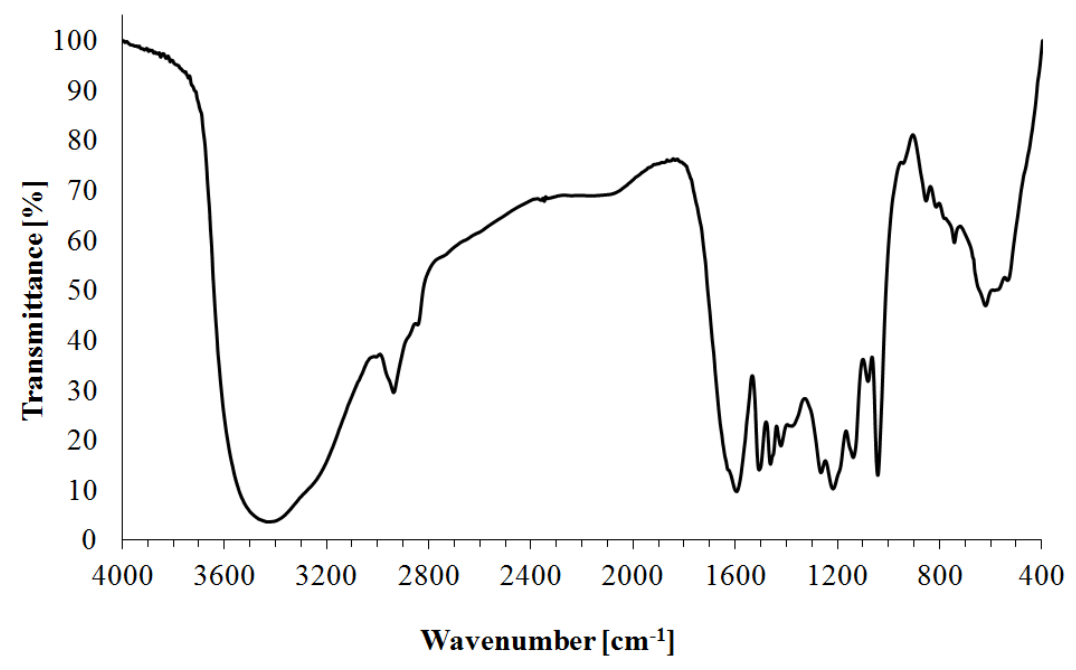

Figure 1: FTIR spectrum of Kraft lignin. 
Kraft lignin was found to be relatively unstable material [26]. Thermogravimetric curves indicate that the changes in this material start at low temperature but some kind of decomposition begins above $300^{\circ} \mathrm{C}$. Compounds found in the vapors during TG experiment are indicated in Table 1. Several phenols were found therein. However, the emission of these toxic substances starts above $300^{\circ} \mathrm{C}$.

Table 1: Compounds detected in TG-MS analysis for pure Kraft lignin.

\begin{tabular}{|l|l|}
\hline Compound & Lignin \\
\hline Carbon dioxide & + \\
\hline Sulphur dioxide & + \\
\hline Methanethiol & + \\
\hline Acetone & + \\
\hline Dimethyl sulfide & + \\
\hline Acetic acid & + \\
\hline 2-Propanone & + \\
\hline Phenol & + \\
\hline Phenol, 2-methyl & + \\
\hline p-Cresol & + \\
\hline Phenol, 2-methoxy & + \\
\hline Benzene, 1,2-dimethoxy & + \\
\hline Phenol, 2,4-dimethyl & + \\
\hline Phenol, 2,3-dimethyl & + \\
\hline Phenol, 4-ethyl & + \\
\hline Cresol & + \\
\hline Benzene, 4-ethyl, 2-methoxy & + \\
\hline 2-methoxy-4-vinylphenol & + \\
\hline Vanillin & + \\
\hline
\end{tabular}

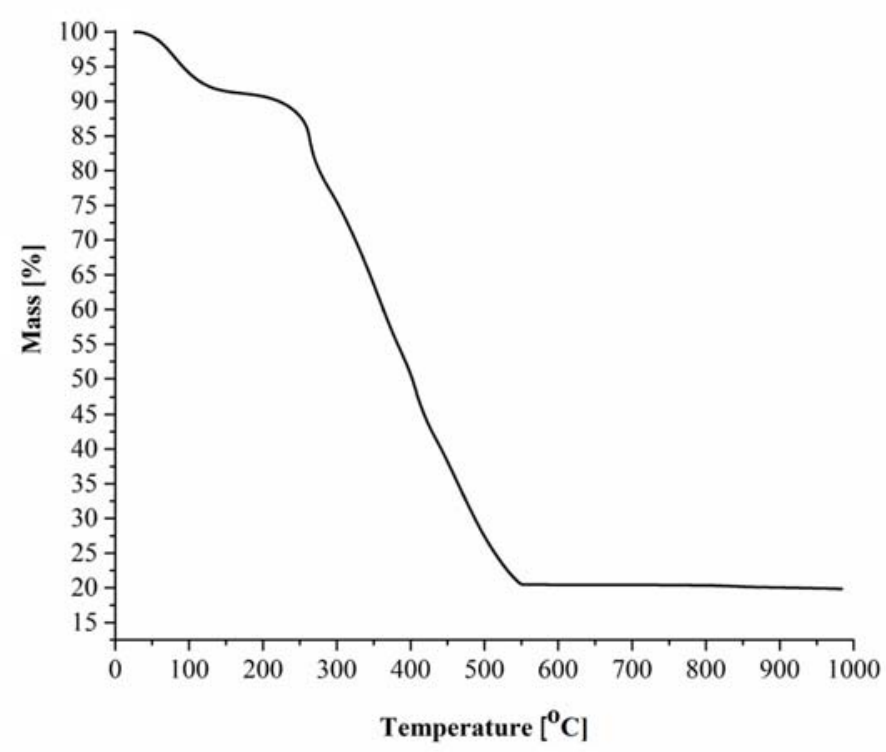

Figure 2: Thermogravimetric curves for Kraft lignin. 
It should be noted that the model applied to the elaboration of the results of inverse gas chromatographic experiment depends on the state of examined materials. Different mathematical procedures are (should be) used for determination of, e.g. solubility parameters for polymers above $T_{g}$ and other for the same polymer below $T_{g}$ or simple solid material like lactose or silica. Therefore, it is common practice to estimate $\ln V_{\mathrm{g}}$ vs. 1/T dependence. The exemplary curves are presented in Fig. 3. It is evident that lignin is not stable even at low temperatures. The region in the center of the curve indicates the existence of transitional region where the retention of the test solute depends on both adsorption on the surface on material and bulk retention. The estimation (calculations) might be carried out at temperatures below this region (here below $60^{\circ} \mathrm{C}$ ). One will obtain the data corresponding to the adsorption on the surface and further corresponding to surface activity of "solid" material. It forced us to estimate HSPs in this region.

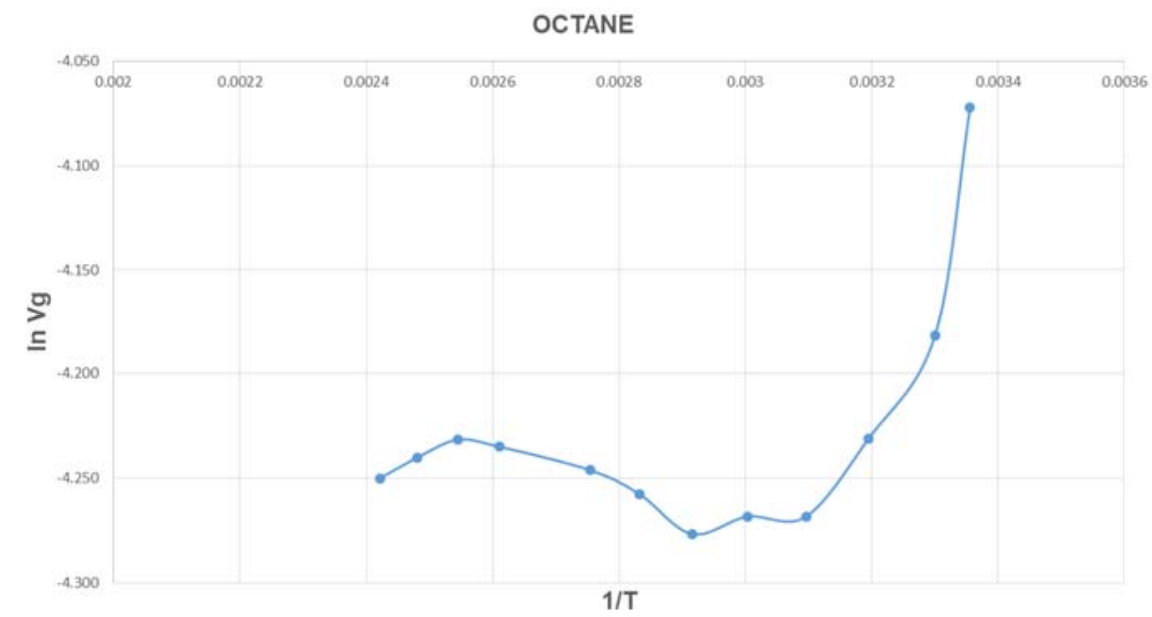

(a)

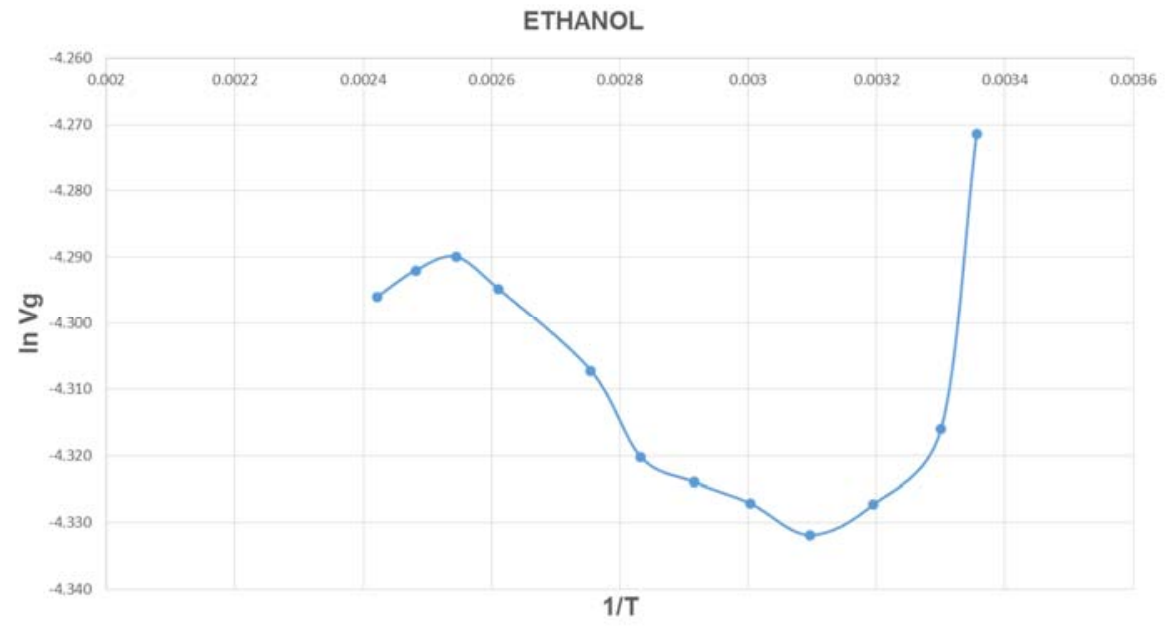

(b)

Figure 3: $\ln V_{g}$ vs. 1/T curves for Kraft lignin. (a) Octane. (b) Ethanol as test solute. 
Table 2: Values of adsorption energy for respective test solutes.

\begin{tabular}{|l|l|}
\hline Test solute & $\begin{array}{l}\text { Adsorption energy } \\
{[\mathrm{kJ} / \mathrm{mol}] 30-60^{\circ} \mathrm{C}}\end{array}$ \\
\hline Heptane & -2.067 \\
\hline Octane & -5.373 \\
\hline Nonane & -11.786 \\
\hline Decane & -17.781 \\
\hline Undecane & -27.425 \\
\hline Ethanol & -1.634 \\
\hline Dichloromethane & -0.811 \\
\hline Ethyl acetate & -1.206 \\
\hline 1,4-Dioxane & -2.529 \\
\hline Acetonitrile & -0.738 \\
\hline
\end{tabular}

Table 3: Hansen solubility parameters and total solubility parameters values found for Kraft lignin from IGC experiments.

\begin{tabular}{|l|c|c|c|c|}
\hline \multirow{2}{*}{ Material } & \multicolumn{4}{|c|}{ Hansen solubility parameter $\left[\mathrm{MPa}^{1 / 2}\right]$} \\
\cline { 2 - 5 } & $\delta_{d}$ & $\delta_{p}$ & $\delta_{h}$ & $\delta_{T}$ \\
\hline Kraft lignin & 16.31 & 18.48 & 7.30 & 25.71 \\
\hline
\end{tabular}

Adsorption energies for the series of test solutes are summarized in Table 2. These data were further used in calculation of HSPs from eqn. (10) and (3). The results of calculations are given in Table 3. These indicate the strong ability of the examined lignin to polar interactions. It is seldom found that value of HSP component corresponding to polar interaction is higher than that describing ability to dispersive interactions. Surprisingly, the component describing the ability of interaction by hydrogen bonding is relatively low. However, the lignin seems to be rather active material what is indicated by high value of total Hansen solubility parameter. Therefore, one may expect that lignin will be exhibit satisfactory activity as the filler in the construction of e.g. abrasive tools.

\section{CONCLUSIONS}

Inverse gas chromatography was found to be satisfactory technique for the estimation of physicochemical characteristic of commercial product - Kraft lignin. Data expressed in the form of Hansen solubility parameters might facilitate prediction of its behavior in real systems, e.g. as potential filler in abrasive articles.

\section{ACKNOWLEDGEMENT}

This work was supported by the National Science Centre Poland under research project no. DEC-2014/15/B/ST8/02321. 


\section{REFERENCES}

[1] Danner, R.P., Tihminlioglu, F., Surana, F.K. \& Duda, J.L., Inverse gas chromatography applications in polymer-solvent systems. Fluid Phase Equilibria, 148, pp. 171-188, 1998.

[2] Thielmann, F., Introduction into the characterization of porous materials by inverse gas chromatography. J. Chromatogr. A, 1037, pp. 115-123, 2004.

[3] Santos, J.M.R.C.A. \& Guthrie, J.T., Analysis of interactions in multicomponent polymeric systems: the key-role of inverse gas chromatography. Mater. Sci. Eng. R., 50(50), pp. 79-107, 2005.

[4] Voelkel, A., Strzemiecka, B., Adamska, K., Milczewska, K. \& Batko, K., Surface and bulk characteristics of polymers by means of inverse gas chromatography. Polymeric Materials, Transworld Research Network: Kerala, pp. 71-102, 2009.

[5] Voelkel, A., Physicochemical Measurements (Inverse Gas Chromatography). Gas Chromatography, Elsevier: Amsterdam, pp. 477-494, 2012.

[6] Voelkel, A., Strzemiecka, B., Adamska, K. \& Milczewska, K., Inverse gas chromatography as a source of physicochemical data. J. Chromatogr. A, 1216, pp. 1551-1566, 2009.

[7] Adamska, K., Bellinghausen, R. \& Voelkel, A., New procedure of the determination of Hansen Solubility Parameters by means of inverse gas chromatography. $J$. Chromatogr. A, 1195, pp. 146-149, 2008.

[8] Sreekanth, T.V.M. \& Reedy, K.S., Evaluation of solubility parameters for nonvolatile branched hydrocarbons by Inverse Gas Chromatography J. Appl. Polym. Sci., 108, pp. 1761-1769, 2008.

[9] Voelkel, A., Batko, K., Adamska, K. \& Strzemiecka, B., Determination of Hansen Solubility Parameters by Means of Gas-Solid Inverse Gas Chromatography. Ads. Sci. Technol., 26, pp. 93-102, 2008.

[10] Adamska, K. \& Voelkel, A., Determination of Hansen solubility parameters by means of Inverse Gas Chromatography. Int. Bull, Pharm. Sci., 1, pp. 30-35, 2012.

[11] Hildebrand, J. \& Scott, R.L., The Solubility of Nonelectrolytes, Reinhold: New York, 1950.

[12] Hildebrand, J. \& Scott, R.L., Regular Solutions, Prentice-Hall Inc.: Englewood Cliffs, NJ, 1962.

[13] Hansen, C.M., The Three-Dimensional Solubility Parameter - Key to Paint Component Affinities I. J. Paint. Technol., 39(505), pp. 104-117, 1967.

[14] Hansen, C.M., The Three-Dimensional Solubility Parameter - Key to Paint Component Affinities II. J. Paint. Technol., 39(511), pp. 505-510, 1967.

[15] Hansen, C.M., The Three-Dimensional Solubility Parameter - Key to Paint Component Affinities III. J. Paint. Technol., 39(511), pp. 511-514, 1967.

[16] Hansen, C.M. \& Beerbower, A., Solubility Parameters. Kirk-Othmer Encyclopedia of Chemical Technology, 2(2), Interscience: New York, pp. 889-910, 1971.

[17] DiPaola-Baranyi, G. \& Guillet, J.E., Estimation of polymer solubility parameters by gas chromatography. Macromolecules, 11, 228-235, 1978.

[18] Price, G.J., Guillet, J.E. \& Purnell, J.H., Measurement of solubility parameters by gasliquid chromatography. J. Chromatogr., 369, 273-280, 1986.

[19] Price, G.J., Lloyd, D.R., Ward, T.C. \& Schreiber, H.P., (eds.) Inverse Gas Chromatography. Characterization of Polymers and Other Materials, ACS Symp. Ser. No 391, Am. Chem. Soc.: Washington D.C., pp. 48-58, 1989.

[20] Voelkel, A. \& Janas, J., The solubility parameters of fluorine-containing oxyethylates. J. Fluorine Chem., 67, pp. 75-81, 1994. 
[21] Choi, P., Kavassalis, T. \& Rudin, A., Measurement of three-dimensional solubility parameters of nonyl phenol ethoxylates using Inverse Gas Chromatography. J. Colloid Interface Sci., 180, pp. 1-8, 1996.

[22] Adamska, K., Bellinghausen, R. \& Voelkel, A., New procedure of the determination of Hansen Solubility Parameters by means of inverse gas chromatography. $J$. Chromatogr. A, 1195, pp. 146-149, 2008.

[23] Karger, B.L. \& Snyder, L.R., an expanded solubility parameter treatment for classification and use of chromatographic solvents and adsorbents. Parameters for dispersion, dipole and hydrogen bonding interactions, J. Chromatogr., 125, pp. 7188, 1976.

[24] Karger B.L., Snyder, L.R. \& Eon, C., Expanded solubility parameter treatment for classification and use of chromatographic solvents and adsorbents. Anal. Chem., 50, pp. 2126-2136, 1978.

[25] Nguyen, H.P. et al., Determination of partial solubility parameters of lactose by gassolid chromatography. J. Pharm. Sci., 75, pp. 68-72, 1986.

[26] Strzemiecka, B., Klapiszewski, Ł. Matykiewicz, D., Voelkel, A. \& Jesionowski, T., Functional lignin-SiO2 hybrids as potential fillers for phenolic binders. J. Adh. Sci. Technol., 30, pp. 1031-1048, 2016. 